\title{
Mapping multicenter randomized controlled trials in anesthesiology: a scoping review
}

\author{
Sylvain Boet ${ }^{1,2,3^{*}} \mathbb{D}$, Joseph K. Burns ${ }^{1,2}$, Olivia Cheng-Boivin ${ }^{4}$, Hira Khan ${ }^{5}$, Kendra Derry', Deric Diep ${ }^{1}$, \\ Abdul Hadi Djokhdem ${ }^{4}$ S Sung Wook Um6, Johnny W. Huang ${ }^{4}$, Danica Paré ${ }^{4}$, Mimi Deng ${ }^{4}$, Liza Begunova ${ }^{7}$, \\ Linda Yi Ning Fei ${ }^{4}$, Maryam Bezzahou ${ }^{4}$, Pium Sonali Andrahennadi ${ }^{4}$, Elysia Grose ${ }^{4}$, Ruth G Abebe ${ }^{8}$, \\ Fadi Mansour ${ }^{4}$, Zoé Talbot ${ }^{4}$, Pierre-Marc Dion ${ }^{9}$, Manvinder Kaur ${ }^{1}$, Justen Choueiry ${ }^{4}$ and Cole Etherington ${ }^{1,2}$
}

\begin{abstract}
Background: Evidence suggests that there are substantial inconsistencies in the practice of anesthesia. There has not yet been a comprehensive summary of the anesthesia literature that can guide future knowledge translation interventions to move evidence into practice. As the first step toward identifying the most promising interventions for systematic implementation in anesthesia practice, this scoping review of multicentre RCTs aimed to explore and map the existing literature investigating perioperative anesthesia-related interventions and clinical patient outcomes.

Methods: Multicenter randomized controlled trials were eligible for inclusion if they involved a tested anesthesiarelated intervention administered to adult surgical patients ( $\geq 16$ years old), with a control group receiving either another anesthesia intervention or no intervention at all. The electronic databases Embase (via OVID), MEDLINE, and MEDLINE in Process (via OVID), and Cochrane Central Register of Control Trials (CENTRAL) were searched from inception to February 26, 2021. Studies were screened and data were extracted by pairs of independent reviewers in duplicate with disagreements resolved through consensus or a third reviewer. Data were summarized narratively.

Results: We included 638 multicentre randomized controlled trials ( $n$ patients $=615,907$ ) that met the eligibility criteria. The most commonly identified anesthesia-related intervention theme across all studies was pharmacotherapy ( $n$ studies $=361[56.6 \%] ; n$ patients $=244,610$ [39.7\%]), followed by anesthetic technique $(n$ studies $=80$ $[12.5 \%], n$ patients $=48,455$ [7.9\%]). Interventions were most often implemented intraoperatively ( $n$ studies $=233$ [36.5\%]; $n$ patients $=175,974$ [28.6\%]). Studies typically involved multiple types of surgeries ( $n$ studies $=187$ [29.2\%]; $n$ patients $=206667$ [33.5\%]), followed by general surgery only ( $n$ studies $=115$ [18.1\%]; $n$ patients $=201,028$ [32.6\%]) and orthopedic surgery only ( $n$ studies $=94$ [14.7\%]; $n$ patients $=34,575[5.6 \%]$ ). Functional status was the most commonly investigated outcome ( $n$ studies $=272$ ), followed by patient experience ( $n$ studies $=168$ ), and mortality $(n$ studies $=153$ ).

Conclusions: This scoping review provides a map of multicenter RCTs in anesthesia which can be used to optimize future research endeavors in the field. Specifically, we have identified key knowledge gaps in anesthesia that require further systematic assessment, as well as areas where additional research would likely not add value. These findings provide the foundation for streamlining knowledge translation in anesthesia in order to reduce practice variation and enhance patient outcomes.
\end{abstract}

\footnotetext{
${ }^{*}$ Correspondence: sboet@toh.ca

${ }^{3}$ Department of Innovation in Medical Education, University of Ottawa,

451 Smyth Rd, Ottawa, ON K1H 8L1, Canada

Full list of author information is available at the end of the article
}

\section{$\triangle B M C$}

(c) The Author(s) 2021, corrected publication 2022. Open Access This article is licensed under a Creative Commons Attribution 4.0 International License, which permits use, sharing, adaptation, distribution and reproduction in any medium or format, as long as you give appropriate credit to the original author(s) and the source, provide a link to the Creative Commons licence, and indicate if changes were made. The images or other third party material in this article are included in the article's Creative Commons licence, unless indicated otherwise in a credit line to the material. If material is not included in the article's Creative Commons licence and your intended use is not permitted by statutory regulation or exceeds the permitted use, you will need to obtain permission directly from the copyright holder. To view a copy of this licence, visit http://creativecommons.org/licenses/by/4.0/. The Creative Commons Public Domain Dedication waiver (http://creativecommons.org/publicdomain/zero/1.0/) applies to the data made available in this article, unless otherwise stated in a credit line to the data. 
Keywords: Anesthesiology, Randomized controlled trials, Multicenter trials, Scoping review

\section{Background}

Each year around the world, over four million people die within 30 days of surgery [1]. Care provided or organized by anesthesiologists throughout the perioperative period is critical to surgical patient outcomes $[2,3]$; yet, practice variation is widespread [4-9]. Despite the need to increase adherence to evidencebased practice in anesthesia, there has not yet been a comprehensive summary of the anesthesia literature that can guide future knowledge translation, i.e., the synthesis, dissemination, and uptake of research evidence into practice $[10,11]$.

After systematic reviews, randomized controlled trials (RCTs) are considered the strongest level of evidence in medicine. RCTs often recruit participants from multiple centers to assess intervention effectiveness across a variety of settings (i.e., external validity) and/or to obtain sufficient statistical power when studying outcomes with a low incidence rate (e.g., mortality) [12, 13]. Although single-center RCTs may be large and powerful, summarizing multicenter RCTs in anesthesia is an important step toward identifying the most promising interventions for systematic implementation in anesthesia practice across a wide range of patient outcomes.

Scoping reviews map key concepts and types of evidence available for complex research areas that have not been comprehensively and systematically reviewed before [14-16]. Due to the broad nature of perioperative and anesthesia research, a scoping review is needed to provide the foundation for future systematic reviews and $\mathrm{KT}$ to move evidence into practice [14, 17]. Mapping anesthesia-related interventions (i.e., interventions performed, organized, or initiated during the perioperative period by a healthcare professional with specific training in anesthesia) and clinical patient outcomes investigated in multicentre RCTs can inform future practice change initiatives. Specifically, a scoping review can inform the development of targeted systematic review questions focusing on particular areas of interest [18]. As the anesthesia literature currently stands, it is unclear where saturation has been reached and where knowledge gaps remain.

This scoping review of multicenter RCTs aims to systematically explore and map the existing literature investigating perioperative anesthesia-related interventions on patient outcomes. This work may help to guide priorities for $\mathrm{KT}$ in anesthesiology as well as for future research.

\section{Methods}

The PRISMA Extension for Scoping Reviews (PRISMAScR) Checklist [19] guided the conduct and reporting of this scoping review.

\section{Eligibility criteria}

We selected studies if they involved a tested anesthesia-related intervention administered to adult surgical patients ( $\geq 16$ years old), with a control group receiving either another anesthesia intervention or no intervention at all. We defined anesthesia-related interventions as "interventions provided in the perioperative period that either were or could have been, performed, organized, or initiated by a healthcare professional with specific training in anesthesia" [20]. The perioperative period was defined as the time period beginning $24 \mathrm{~h}$ before the surgical procedure to $24 \mathrm{~h}$ following the procedure. We excluded studies involving surgical procedures with only local anesthesia. We included all multicenter randomized controlled trials (i.e., trials involving two or more centers) assessing the impact of anesthesia interventions on one or more patient outcomes. We elected to only include multicentre randomized controlled trials to ensure impactful resource allocation, minimization of research duplication, and potentially better research coordination.

\section{Information sources and search strategy}

We searched the electronic databases Embase (via OVID), MEDLINE, and MEDLINE in Process (via OVID), and Cochrane Central Register of Control Trials (CENTRAL). A separate search strategy was constructed for each database, reviewed by the research team, and refined as necessary (see Appendix). The MEDLINE search strategy was reviewed by a second trained information scientist as per Peer Review of Electronic Search Strategies (PRESS) guidelines [21-23]. Clinical trial registries and reference lists of included studies and previously published systematic reviews were also searched. Date and language restrictions were not imposed for the literature search; however, only studies reported in English were included in the scoping review. The search included studies published up until February 26, 2021.

\section{Selection of sources of evidence}

Studies were selected by seven pairs of independent reviewers using DistillerSR (Evidence Partners, Ottawa, Canada), a web-based systematic review software. A screening tool featuring questions based on inclusion and exclusion criteria was developed, piloted, and refined 
as necessary. Reviewer calibration occurred during this process, whereby screeners clarified questions and reasons for decision-making until satisfactory inter-rater reliability was achieved (kappa $>0.60$ ). Seven pairs of independent reviewers conducted eligibility screening of titles and abstracts in duplicate. Studies were "excluded" at this stage if the two independent reviewers determined they did not meet eligibility criteria. Otherwise, studies proceeded to full-text screening. Disagreements about inclusion or exclusion at each stage were resolved by consensus or through a third member of the research team (NE, OCB) as needed. The final list of included articles was reviewed by the investigator team to determine if any additional articles should have been included. The citations of the excluded articles are provided in Additional file 2 .

\section{Data charting process}

Seven pairs of independent reviewers conducted data extraction using an electronic form (DistillerSR, Evidence Partners, Ottawa, Canada) created and piloted by the research team. The following information was extracted: publication details (e.g., first author name, publication year, country of data collection), study details (e.g., design and sample size), patient demographics (e.g., sex, age, coexisting medical conditions), intervention details (e.g., type, duration), comparator (i.e., no intervention or other anesthesia intervention), and patient outcome (e.g., outcome definition and timing). Accuracy was compared and verified by the reviewer pairs upon completion of data extraction. Quality assessments are typically not completed for scoping reviews and were therefore not conducted [17, 24].

\section{Synthesis of results}

Anesthesia-related interventions were classified according to themes developed in a previous scoping review [20]. Similar outcomes were grouped into larger categories.

The results of this scoping review were summarized using a narrative approach, along with a quantitative summary of relevant study characteristics.

\section{Ethical approval}

The design of this study did not require the approval of an ethics committee as it is a scoping review. However, the research team did raise and consider the ethical aspects surrounding this study prior to data collection.

\section{Results}

The literature search retrieved 4694 publications. After removal of duplicates, 3197 articles proceeded to the screening process. Following title and abstract screening for inclusion, 2372 articles were excluded. Full-text review for inclusion/exclusion criteria led to the exclusion of another 187 articles. A final total of 638 articles were therefore included in this scoping review (Fig. 1).

A total of 615,907 participants were randomized across all 638 trials. Publication of multicenter trials began after the year 1980 and was highest in the years 2010-2020 (Fig. 2), although the time period extending beyond the search data appears poised to supersede the previous decade. Data collection occurred most often in the USA $(n$ studies $=165[25.9 \%] ; n$ patients $=102,063[16.8 \%])$ (Supplemental Fig. 1). The median number of centers involved in a single study was 11 (IQR $=6-18$ ).

The most commonly identified anesthesia-related intervention theme across all multicentre RCTs by study number was pharmacotherapy ( $n$ studies $=361$ [56.6\%]; $n$ patients $=244610[39.7 \%]$ ), followed by anesthetic technique ( $n$ studies $=80$ [12.5\%]; $n$ patients $=48455$ [7.9\%]) (Table 1). Interventions were most often implemented intraoperatively alone $(n$ studies $=233[36.5 \%]$; $n$ patients $=175974$ [28.6\%]) as opposed to pre- and/ or postoperatively (Table 2). As shown in Fig. 3, multicenter RCTs typically involved several types of surgery $(n$ studies $=187[29.3 \%] ; n$ patients $=206667$ [33.6\%]), followed by general surgery only ( $n$ studies $=115$ [18.0\%]; $n$ patients $=201,028[32.6 \%]$ ) and orthopedic surgery only ( $n$ studies $=94[14.7 \%] ; n$ patients $=34,575[5.6 \%]$ ). Less than 10 multicenter RCTs investigated anesthesia-related interventions within the context of bariatric surgery, neurosurgery, ophthalmology, otolaryngology, thoracic surgery, urology, and vascular surgery.

A summary of patient outcomes investigated by the included studies is displayed in Table 3. Outcomes reported here include both primary and secondary outcomes. Of note, studies often investigated more than one outcome and were therefore counted more than once. Functional status was the most commonly investigated outcome according to its number of studies ( $n$ studies $=272$ ), followed by patient experience ( $n$ studies $=168)$ and mortality ( $n$ studies $=153)$. Studies investigating mortality involved the greatest number of patients ( $n$ patients $=412,416)$, followed by those investigating length of stay ( $n$ patients $=283,463$ ), and cardiovascular outcomes $(n$ patients $=276,808)$.

\section{Discussion}

This scoping review identified 638 multicenter RCTs investigating the impact of anesthesia-related interventions on clinical patient outcomes. Most RCTs took place in the USA and investigated pharmacotherapy interventions implemented intraoperatively. Functional status was the most commonly investigated outcome, followed by patient experience and mortality. By mapping 


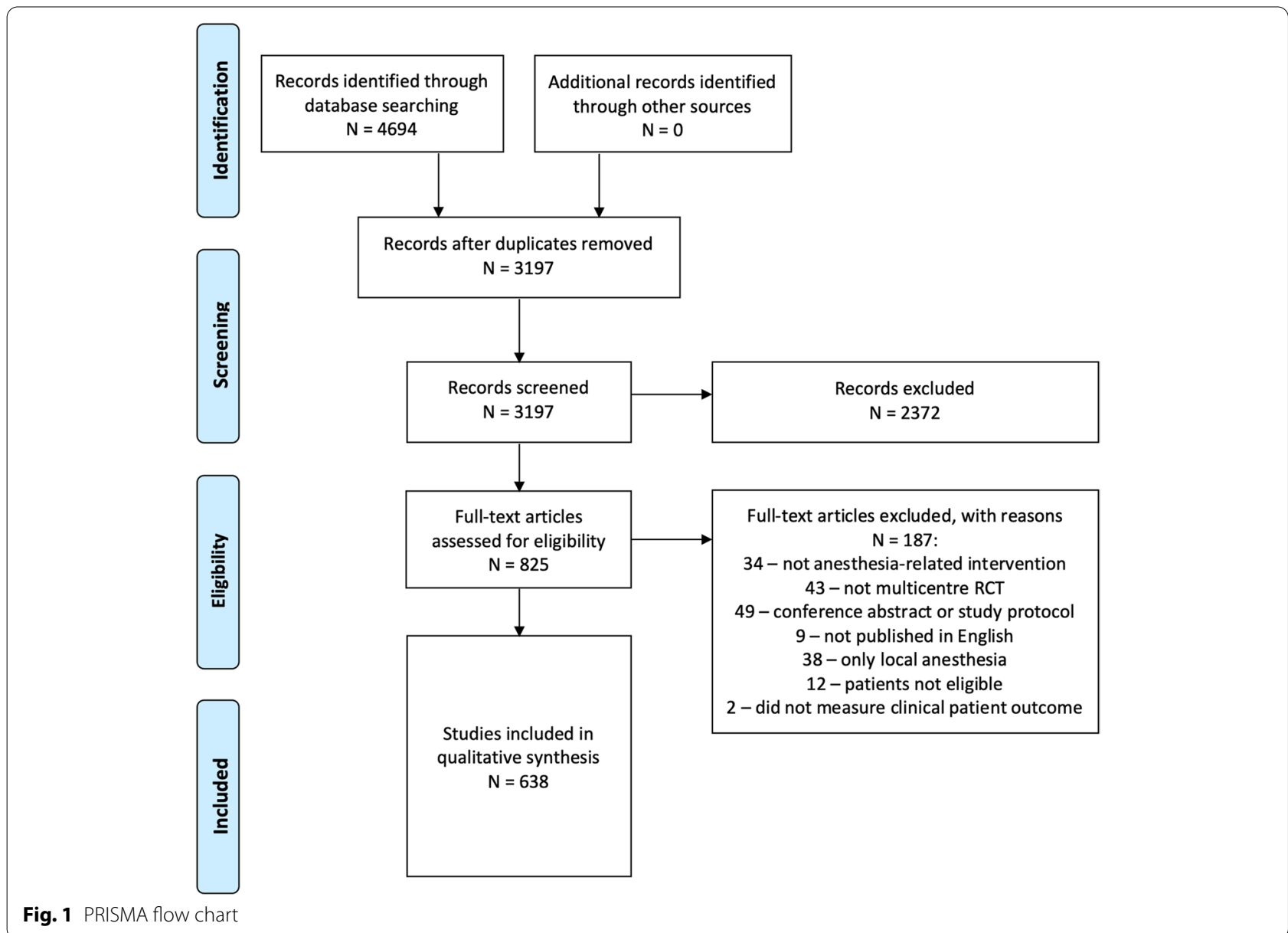

Fig. 1 PRISMA flow chart

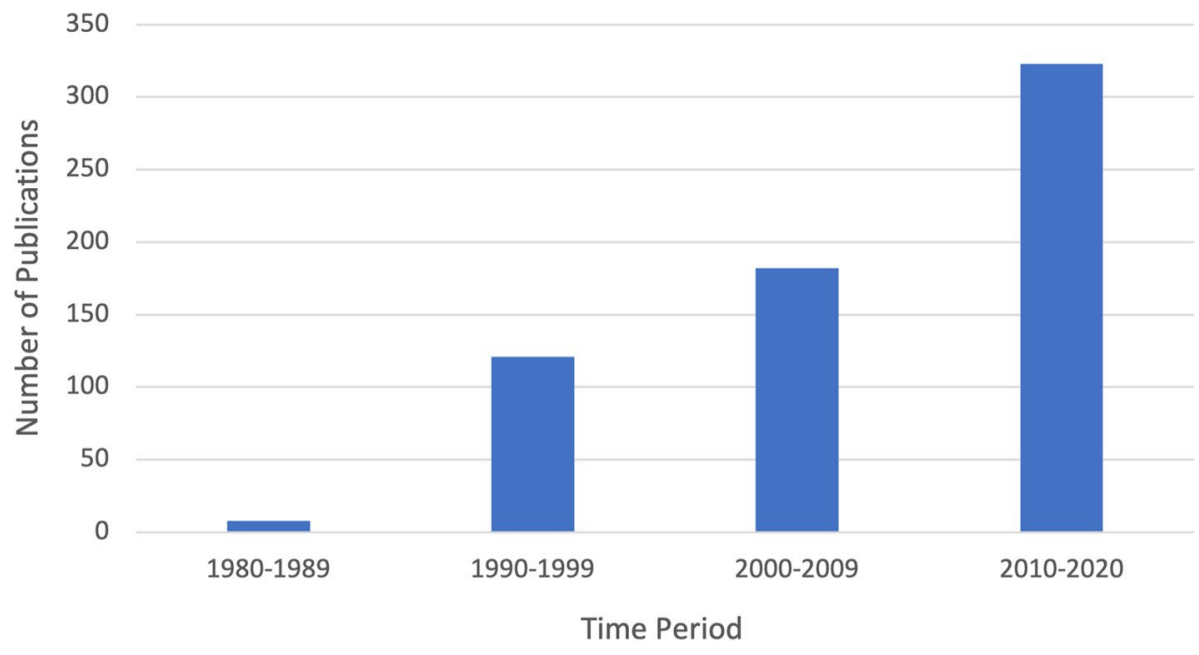

Fig. 2 Evolution of the number of multicenter randomized controlled trials in anesthesia

the anesthesia literature at a high level of evidence, such as multicenter RCTs, this review can be used to guide future research and intervention development with the potential to optimize surgical patient care and outcomes. Specifically, we have identified a clear under-investigation of non-pharmacotherapy interventions in the anesthesia 
Table 1 Anesthesia-related intervention themes in multicenter randomized controlled trials ( $n$ studies $=445, n$ patients $=336$ 966)

\begin{tabular}{lll}
\hline Intervention category & $\begin{array}{l}\text { Number } \\
\text { of studies } \\
\text { (\%) }\end{array}$ & Number of patients (\%) \\
\hline Anesthetic technique & $80(12.5)$ & $48455(7.9)$ \\
Behavioral change & $4(0.7)$ & $438(0.07)$ \\
Dialysis & $0(0)$ & $0(0)$ \\
Glucose control & $0(0)$ & $0(0)$ \\
Intravenous (IV) fluids & $12(1.9)$ & $3671(0.5)$ \\
Medical device & $6(1.1)$ & $1166(0.1)$ \\
Monitoring & $11(1.7)$ & $15912(2.6)$ \\
Nutritional & $20(3.1)$ & $4731(0.7)$ \\
Pharmacotherapy & $361(56.6)$ & $244610(39.7)$ \\
Physiotherapy & $4(0.7)$ & $994(0.2)$ \\
Preoperative procedure & $18(2.8)$ & $9904(1.6)$ \\
Protocol/guidelines implemen- & $12(1.8)$ & $159134(25.8)$ \\
tation & & \\
Temperature management & $5(0.8)$ & $2451(0.4)$ \\
Testing & $0(0)$ & $0(0)$ \\
Transfusion & $19(3.0)$ & $13994(2.3)$ \\
Ventilation & $19(3.0)$ & $11817(1.9)$ \\
Combination of interventions & $67(10.5)$ & $98641(16.0)$ \\
Total & 638 & 615907 \\
\hline
\end{tabular}

This list of themes was generated in our previously conducted scoping review [20]

Table 2 Perioperative phase of anesthesia-related interventions in multicenter randomized controlled trials ( $n$ studies $=445, n$ patients $=336$ 966)

\begin{tabular}{lll}
\hline Perioperative phase & $\begin{array}{l}\text { Number of } \\
\text { studies (\%) }\end{array}$ & Number of patients (\%) \\
\hline Preoperative & $67(10.5)$ & $47702(7.7)$ \\
Intraoperative & $233(36.5)$ & $175974(28.6)$ \\
Postoperative & $165(25.9)$ & $209743(34.1)$ \\
$\begin{array}{l}\text { Multi-phase (i.e., intervention } \\
\text { spanned across 2 or 3 phases) }\end{array}$ & $169(26.5)$ & $179650(29.2)$ \\
Not reported & $4(0.6)$ & $2630(0.4)$ \\
Total & 638 & 615907 \\
\hline
\end{tabular}

literature. Future RCTs and systematic reviews may therefore consider how anesthesia-related interventions outside of pharmacotherapy impact patient outcomes (e.g., teamwork interventions). Knowledge translation interventions can then be developed to move this evidence into clinical practice and to standardize the use of non-pharmacotherapy interventions when they may benefit patients the most. The aim of a scoping review is to map evidence in a field rather than to conduct a thorough analysis of each included study. Accordingly, quality of evidence was not assessed and results should be interpreted accordingly [14].

We observed a clear gap in the literature, for example, related to behavior change or nutritional interventions, which were investigated by a limited number of studies. This finding is similar to a previous scoping review on anesthesia-related interventions that specifically analyzed mortality, including both single and multicenter trials [20]. Unlike the previous review, however, we did not limit our work to a specific type of surgery (e.g., emergency only [25]) and included a wide range of clinical patient outcomes beyond mortality. It is surprising that studies frequently investigated functional status and patient experience outcomes but tended to focus on provider-centric interventions (e.g., pharmacotherapy). Other scoping reviews have also focused on providercentric interventions such as mode of anesthesia [25], with limited discussion of interventions that may provide patients with a greater sense of control over their care and outcomes. With both surgical patients [26, 27] and anesthesia providers $[28,29]$ increasingly interested in alternative therapies, perhaps more investigation is needed regarding non-pharmacotherapy interventions. This may provide opportunities for enhancing patientcentered care and advancing anesthesia practice.

It is noteworthy that patient-centered outcomes were among the most commonly investigated by multicenter trials within the anesthesia literature given recent calls to systematically incorporate these outcomes into perioperative research and practice (e.g., decision-making, surgical care plans) [30]. Many surgical specialties have moved toward developing standardized patient-centered endpoints [31-33]. Based on this review, there appears to be a strong foundation for anesthesiology to move toward doing the same. For example, over 450 studies included in this review examined how anesthesia-related interventions impact patient experience (e.g., patient satisfaction, patient evaluation of care), length of stay, psychiatric-related outcomes, or patient functional status (e.g., health-related quality of life, pain, mobility, quality of recovery). Recently, Jerath and colleagues validated days alive and out of hospital as a patient-centered outcome for perioperative medicine [34]. Of course, this is just one potential patient-centered outcome to consider amidst the several highlighted by our review.

Our review also highlights that anesthesia-related interventions implemented in the intra- or post-operative period are the most studied by multicenter trials. However, only 67 studies investigated interventions implemented preoperatively. This may suggest a key opportunity regarding both the existence and effectiveness of preventative interventions. There may be a need 


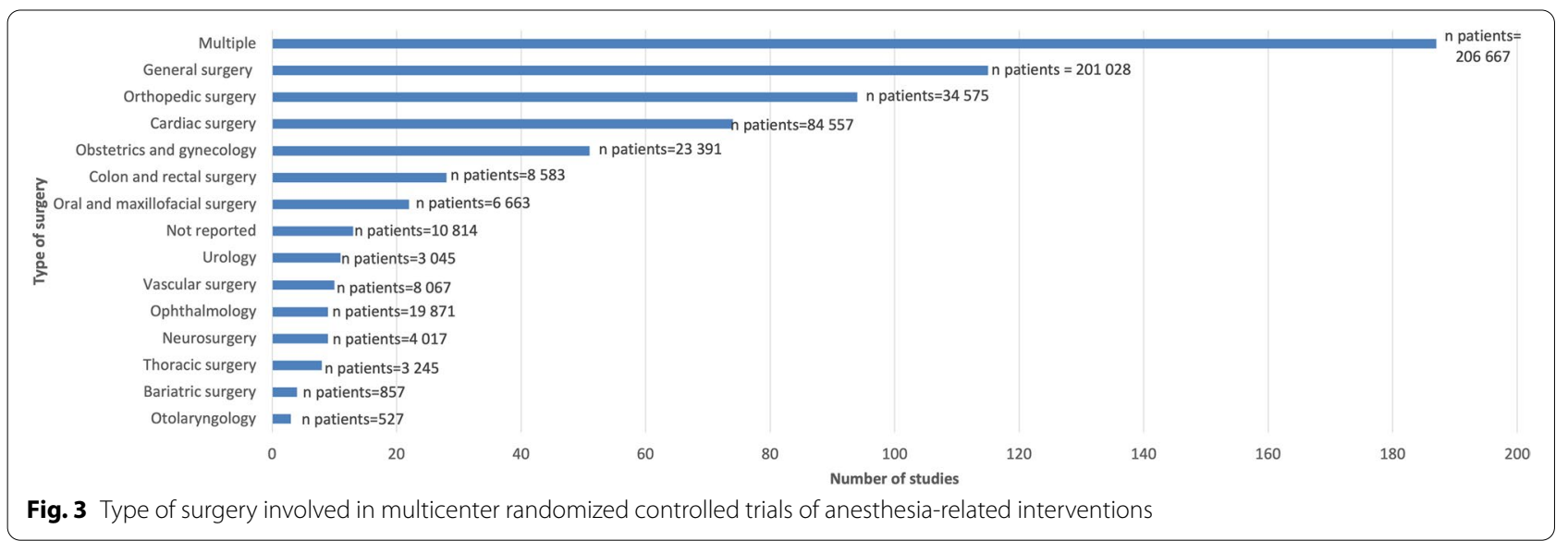

Table 3 Outcomes investigated by anesthesia multicentre randomized controlled trials $(n=445)$

\begin{tabular}{lll}
\hline Outcome category & $\begin{array}{l}\text { Number of } \\
\text { studies }\end{array}$ & Number of patients \\
\hline Blood clot/bleeding & 73 & 60969 \\
Cardiovascular & 131 & 276808 \\
Functional status & 272 & 95202 \\
Gastrointestinal & 38 & 47996 \\
Hematological & 57 & 67258 \\
Infection & 102 & 141554 \\
Injury or damage to tissue or organ & 28 & 24325 \\
Length of stay & 142 & 283463 \\
Mortality & 153 & 412416 \\
Neurological & 55 & 130369 \\
Patient experience & 168 & 83598 \\
Psychiatric-related outcome & 29 & 27570 \\
Pulmonary & 92 & 208132 \\
Renal & 60 & 67354 \\
Wound & 26 & 30224 \\
Other & 166 & 261629 \\
\hline
\end{tabular}

to further explore preoperative optimization of surgical patients given the persistent rate of complications that still occur despite advancements in anesthetic and surgical care [35, 36]. For example, future multicenter trials may consider investigating nutritional or physical exercise interventions in the preoperative period to optimize patient outcome [37]. Another important consideration for preventing postoperative complications may be the role of teamwork and communication. Research suggests that ineffective teamwork in the OR is a primary contributing factor in two out of three cases of postoperative complications [38]; however, we did not identify any multicenter study examining teamwork-related interventions. This is a significant knowledge gap for the perioperative community to address. In addition, most of the included studies were conducted in North America or Europe, yet surgical and anesthesia complications are even more prevalent in other parts of the world [1]. Given the lack of studies from low- and middle-income countries, there is an urgent need for more research in these contexts in order to reduce the overall global burden of anesthesia-related morbidity and mortality.

Anesthesia-related interventions were typically examined within the context of multiple types of surgery, orthopedic surgery only, or general surgery only. These interventions appear to be less investigated within particular surgical specialties, such as bariatric surgery, neurosurgery, ophthalmology, otolaryngology, thoracic surgery, urology, and vascular surgery. Future multicenter trials may therefore aim to test effectiveness of anesthesiarelated interventions within different surgical specialties.

\section{Strengths and limitations}

There are several limitations of this scoping review. The breadth and volume of the included studies prevented further assessment of intervention effectiveness. It will be important for future systematic reviews to examine the effectiveness of specific intervention themes for particular outcome categories. Our scoping review provides a useful map for this purpose given its extensive summary of a very large number of studies investigating a diverse range of interventions and patient outcomes. For example, future systematic reviews may also wish to quantify the effect of non-pharmacotherapy interventions compared to pharmacotherapy interventions for specific patient-centered patient outcomes. Our review also included only those studies published in English for feasibility reasons. Given our aim was to provide a map of the literature rather than to summarize treatment effects, we believe that inclusion of studies published in other languages would change our 
results. With the map we have provided, researchers can conduct more targeted systematic reviews in the future. Within a narrower review, inclusion of non-English studies would be less resource-intensive. Ultimately, our scoping review is an important step toward improving the practice of anesthesia and benefited from a comprehensive search strategy, clear inclusion and exclusion criteria, and significant content expertise among our team of co-investigators. Another limitation is our narrow eligible perioperative period of $24 \mathrm{~h}$ before and after the surgical procedure to $24 \mathrm{~h}$ following the procedure. It is likely that a wider time window would result in additional interventions taking place in the days before or after surgery, such as prehabilitation with exercise therapy.

\section{Conclusion}

This scoping review provides a map of multicenter RCTs in anesthesia which can be used to optimize future research endeavors in the field. Specifically, we have identified key knowledge gaps in anesthesia that require further systematic assessment, as well as areas where additional research would likely not add value. These findings provide the foundation for streamlining knowledge translation in anesthesia in order to reduce practice variation and enhance patient outcomes.

\section{Appendix}

\section{Literature search strategy MEDLINE search strategy}

1. exp Surgical Procedures, Operative/

2. ((operat" or surger* or surgical*) adj3 an?esth*).tw.

3. (surger* or surgical*).tw.

4. or $/ 1-3$

5. exp Postoperative Period/

6. exp Perioperative Care/

7. Preoperative Care/

8. exp Anesthesia/

9. $\exp$ Analgesia/

10. ((perioperative or intraoperative or postoperative or peroperative) adj3 (care or therap* or treatment" or procedure* or management*)).tw.

11. an?esth".tw.

12. analges".tw.

13. or $/ 5-12$

14. exp Morbidity/

15. exp Postoperative Complications/

16. Mortality/

17. Survival Rate/

18. Hospital Mortality/

19. Mortality, Premature/

20. morbid".tw.
21. mortal".tw.

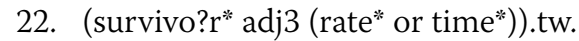

23. survivo?rship".tw.

24. (premature adj3 death").tw.

25. (death adj2 rate*).tw.

26. fatalit*.tw.

27. exitus.tw.

28. or/14-27

29. clinical trial, phase i/ or clinical trial, phase ii/ or clinical trial, phase iii/ or clinical trial, phase iv/ or controlled clinical trial/ or exp randomized controlled trial/

30. exp Clinical Trials as Topic/

31. Double-Blind Method/

32. Single-Blind Method/

33. Random Allocation/

34. Clinical Trial/

35. clinical trial*.tw.

36. (singl" or doubl" or trebl" or tripl*).tw.

37. 35 or 36

38. (mask* or blind*).tw.

39. 37 and 38

40. randomized controlled trial.pt.

41. controlled clinical trial.pt.

42. clinical trial.pt.

43. random*.tw.

44. control".tw.

45. 29 or 30 or 31 or 32 or 33 or 34 or 39 or 40 or 41 or 42 or 43 or 44

46. Multicenter Studies as Topic/

47. multicenter study.pt.

48. multicenter study/

49. multi?cent".tw.

50. 46 or 47 or 48 or 49

51. 45 and 50

52. 4 and 13 and 28 and 51

\section{Embase search strategy}

1. surgical technique/

2. ((operat" or surger* or surgical") adj3 an?esth*).ti,ab.

3. (surger" or surgical").ti,ab.

4. or/1-3

5. postanesthesia care/ or postoperative analgesia/ or postoperative care/

6. perioperative period/

7. preoperative period/ or preoperative care/

8. anesthesia/

9. ((perioperative or intraoperative or postoperative or peroperative) adj3 (care or therap* or treatment* or procedure* or management*)).tw.

10. postoperative analgesia/ 
11. or $/ 5-10$

12. morbidity/

13. postoperative complication/

14. mortality/

15. survival rate/

16. morbid".tw.

17. mortal".tw.

18. or/12-17

20. "clinical trial (topic)"/ or exp "controlled clinical trial (topic)"/ or "phase 1 clinical trial (topic)"/ or "phase 2 clinical trial (topic)"/ or "phase 3 clinical trial (topic)"/ or "phase 4 clinical trial (topic)"/

21. exp controlled clinical trial/ or phase 1 clinical trial/ or phase 2 clinical trial/ or phase 3 clinical trial/ or phase 4 clinical trial/

22. or $/ 19-21$

23. "multicenter study (topic)"/

24. multicenter study/

26. 4 and 11 and 18 and 22 and 25
19. clinical trial/

25. or $/ 23-24$

Availability of data and materials

The data for this study are available upon request from the study team.

\section{Declarations}

\section{Ethics approval and consent to participate}

The design of this study did not require the approval of an ethics committee as it is a scoping review. However, the research team did raise and consider the ethical aspects surrounding this study prior to data collection.

\section{Consent for publication}

Not applicable.

\section{Competing interests}

The authors declare that they have no competing interests.

\section{Author details}

${ }^{1}$ Department of Anesthesiology and Pain Medicine, University of Ottawa, 451 Smyth Rd, Ottawa, ON K1H 8L1, Canada. ${ }^{2}$ Clinical Epidemiology Program, Ottawa Hospital Research Institute, 501 Smyth Rd, Ottawa, ON K1H 8L6, Canada. ${ }^{3}$ Department of Innovation in Medical Education, University of Ottawa, 451 Smyth Rd, Ottawa, ON K1H 8L1, Canada. ${ }^{4}$ Faculty of Medicine, University of Ottawa, 451 Smyth Rd, Ottawa, ON K1H 8L1, Canada. ${ }^{5}$ Department of Health Sciences, Carleton University, 1125 Colonel By Drive, Ottawa, ON K1S 5B6, Canada. ${ }^{6}$ Department of Anesthesiology and Pain Medicine, University of Toronto, Toronto, Canada. ${ }^{7}$ Department of Psychological and Brain Sciences, Dartmouth College, Hanover, NH 03755, USA. ${ }^{8}$ Faculty of Health Sciences, University of Ottawa, 125 University, Ottawa, ON K1N 6N5, Canada. ${ }^{9}$ Intensive Care Unit, Montfort Hospital, Ottawa, Canada.

Received: 1 December 2020 Accepted: 26 July 2021

Published online: 26 October 2021

\section{Abbreviations}

KT: Knowledge translation; RCT: Randomized controlled trial.

\section{Supplementary Information}

The online version contains supplementary material available at https://doi. org/10.1186/s13643-021-01776-5.

Additional file 1: Supplemental Fig. 1. Country of data collected for anesthesia-related interventions tested in multicentre randomized controlled trials.

Additional file 2.

\section{Acknowledgements}

The authors would like to thank Jose Dewit and Abdellah Bezzahou for their initial contributions to screening and Lindsey Sikora for assistance with the literature search. They would also like to thank Amin Zahrai and Catherine Kennedy for their assistance with revising the manuscript.

\section{Authors' contributions}

All authors contributed to the present work in the following ways: Substantial contributions to the conception or design of the work; or the acquisition, analysis, or interpretation of data for the work; Drafting the work or revising it critically for important intellectual content; Final approval of the version to be published; Agreement to be accountable for all aspects of the work in ensuring that questions related to the accuracy or integrity of any part of the work are appropriately investigated and resolved.

\section{Funding}

Dr. Boet was supported by The Ottawa Hospital Anesthesia Alternate Funds Association and the Faculty of Medicine, University of Ottawa, with a Tier 2 Clinical Research Chair.
References

1. Nepogodiev D, Martin J, Biccard B, Makupe A, Bhangu A, Ademuyiwa A, et al. Global burden of postoperative death. Lancet. 2019;393:401.

2. Wacker J, Staender S. The role of the anesthesiologist in perioperative patient safety. Curr Opin Anaesthesiol. 2014;27:649-56. Available at: http://www.ncbi.nlm.nih.gov/pubmed/25233191. Accessed 10 Oct 2017

3. Greig PR, Higham HE, Darbyshire JL, Vincent C. Go/no-go decision in anaesthesia: wide variation in risk tolerance amongst anaesthetists. $\mathrm{Br} J$ Anaesth. 2017;118:740-6.

4. Beaupre LA, Jones CA, Saunders LD, Johnston DWC, Buckingham J, Majumdar SR. Best practices for elderly hip fracture patients. J Gen Intern Med. 2005;20:1019-25. Available at: http://link.springer.com/10.1111/j. 1525-1497.2005.00219.x. Accessed 25 May 2017.

5. Mazzocco K, Petitti DB, Fong KT, Bonacum D, Brookey J, Graham S, et al. Surgical team behaviors and patient outcomes. Am J Surg. 2009;197:67885. Available at: http://linkinghub.elsevier.com/retrieve/pii/S000296100 8004595. Accessed 4 Feb 2017.

6. Pronovost PJ, Rinke ML, Emery K, Dennison C, Blackledge C, Berenholtz SM. Interventions to reduce mortality among patients treated in Intensive Care Units. J Crit Care. 2004;19:158-64. Available at: http://www.scien cedirect.com.proxy1.lib.uwo.ca/science/article/pii/S0883944104000486. Accessed 25 May 2017

7. Shehata N, Wilson K, Mazer CD, Tomlinson G, Streiner D, Hébert P, et al. The proportion of variation in perioperative transfusion decisions in Canada attributable to the hospital. Can J Anesth. 2007;54:902-7. Available at: http://link.springer.com/10.1007/BF03026794. Accessed 25 May 2017.

8. Kalhan R, Mikkelsen M, Dedhiya P, Christie J, Gaughan C, Lanken PN, et al. Underuse of lung protective ventilation: analysis of potential factors to explain physician behavior*. Crit Care Med. 2006;34:300-6. Available at: http://content.wkhealth.com/linkback/openurl?sid=WKPTLP:landingpag e\&an $=00003246-200602000-00003$. Accessed 25 May 2017. 
9. Weller JM, Merry AF. I. Best practice and patient safety in anaesthesia. $\mathrm{Br}$ J Anaesth. 2013;110:671-3. Available at: https://academic.oup.com/bja/ article-lookup/doi/10.1093/bja/aet011. Accessed 25 May 2017.

10. Graham ID, Logan J, Harrison MB, Straus SE, Tetroe J, Caswell W, et al. Lost in knowledge translation: time for a map? J Contin Educ Health Prof. 2006;26:13-24.

11. Tricco AC, Cogo E, Ashoor H, Perrier L, McKibbon KA, Grimshaw JM, et al. Sustainability of knowledge translation interventions in healthcare decision-making: protocol for a scoping review. BMJ Open. 2013:3:e002970. Available at: http://www.ncbi.nlm.nih.gov/pubmed/23674448. Accessed 25 May 2017.

12. Evans D. Hierarchy of evidence: a framework for ranking evidence evaluating healthcare interventions. J Clin Nurs. 2003;12:77-84.

13. Bellomo R, Bagshaw SM. Evidence-based medicine: classifying the evidence from clinical trials - the need to consider other dimensions. Crit Care. 2006;10:1-8.

14. Armstrong R, Hall BJ, Doyle J, Waters E. "Scoping the scope" of a cochrane review. J Public Health (Bangkok). 2011;33:147-50. Available at: https:// academic.oup.com/jpubhealth/article-lookup/doi/10.1093/pubmed/ fdr015. Accessed 25 May 2017.

15. Rumrill PD, Fitzgerald SM, Merchant WR. Using scoping literature reviews as a means of understanding and interpreting existing literature. Work. 2010;35:399-404. Available at: https://content.iospress.com/articles/ work/wor00998. Accessed 22 Feb 2017.

16. Brien SE, Lorenzetti DL, Lewis S, Kennedy J, Ghali WA. Overview of a formal scoping review on health system report cards. Implement Sci. 2010;5:2. Available at: http://implementationscience.biomedcentral.com/ articles/10.1186/1748-5908-5-2. Accessed 22 Feb 2017.

17. Arksey H, O'Malley L. Scoping studies: towards a methodological framework. Int J Soc Res Methodol. 2005;8:19-32. Available at: http://www. tandfonline.com/doi/abs/10.1080/1364557032000119616. Accessed 25 May 2017.

18. Munn Z, Peters MDJ, Stern C, Tufanaru C, McArthur A, Aromataris E. Systematic review or scoping review? Guidance for authors when choosing between a systematic or scoping review approach. BMC Med Res Methodol. 2018:18:1-7.

19. Tricco AC, Lillie E, Zarin W, O'Brien KK, Colquhoun H, Levac D, et al. PRISMA extension for scoping reviews (PRISMA-SCR): checklist and explanation. Ann Intern Med. 2018;169:467-73.

20. Boet S, Etherington N, Nicola D, Beck A, Bragg S, Carrigan ID, et al. Anesthesia interventions that alter perioperative mortality: a scoping review. Syst Rev. 2018;7:218. Available at: https://systematicreviewsjournal.biome dcentral.com/articles/10.1186/s13643-018-0863-x.

21. McGowan J, Sampson M, Salzwedel D, Cogo E, Foerster V, Lefebvre C. PRESS - peer review of electronic search strategies guideline: explanation \& elaboration. 2016

22. Sampson M, McGowan J, Cogo E, Grimshaw J, Moher D, Lefebvre C. An evidence-based practice guideline for the peer review of electronic search strategies. J Clin Epidemiol. 2009;62:944-52. https://doi.org/10. 1016/j.jclinepi.2008.10.012.

23. McGowan J, Sampson M, Lefebvre C. An evidence based checklist for the Peer Review of Electronic Search Strategies (PRESS EBC). Evid Based Libr
Inf Pract. 2010;5:149-54. Available at: http://ejournals.library.ualberta.ca/ index.php/EBLIP/article/view/7402.

24. Grant MJ, Booth A. A typology of reviews: an analysis of 14 review types and associated methodologies. Health Info Libr J. 2009;26:91-108.

25. Morley RL, Elliott L, Rees J, Rudd S, Mouton R, Hinchliffe RJ. Scoping review of mode of anaesthesia in emergency surgery. Br J Surg. 2020;107:e17-25.

26. Soós SÁ, Jeszenői N, Darvas K, Harsányi L. Nem konvencionális gyógymódok használata sebészeti betegek között. Orv Hetil. 2016;157:1483-8.

27. Vetter D, Barth J, Uyulmaz S, Uyulmaz S, Vonlanthen R, Belli G, et al. Effects of art on surgical patients: a systematic review and meta-analysis. Ann Surg. 2015;262:704-13.

28. Soós SÁ, Jeszenoi N, Darvas K, Harsányi L. Complementary and alternative medicine: attitudes, knowledge and use among surgeons and anaesthesiologists in Hungary. BMC Complement Altern Med. 2016;16:1-8.

29. Woodbury A, Soong SN, Fishman D, García PS. Traitements de médecine complémentaire et alternative pertinents pour l'anesthésiologiste et le clinicien de la douleur: un compte rendu narratif. Can J Anesth. 2016;63:69-85.

30. Robinson TN, Berian JR. Incorporating patient-centered outcomes into surgical care. Ann Surg. 2017;265:654-5.

31. Sun LY, Tu JV, Lee DS, Beanlands RS, Ruel M, Austin PC, et al. Disability-free survival after coronary artery bypass grafting in women and men with heart failure. Open Heart. 2018;5:e000911. http://openheart.bmj.com/ lookup/doi/10.1136/openhrt-2018-000911.

32. Wang SY, Stem MS, Oren G, Shtein R, Lichter PR. Patient-centered and visual quality outcomes of premium cataract surgery: a systematic review. Eur J Ophthalmol. 2017;27:387-401.

33. Dore L, Fernandez B, Velanovich V. Patient-centered outcome instruments in esophageal and gastric surgery. J Gastrointest Surg. 2017;21:1515-22.

34. Jerath A, Austin PC, Wijeysundera DN. Days alive and out of hospital. Anesthesiology. 2019;131:84-93.

35. Tevis S, Kennedy G. Postoperative complications and implications on patient- centered outcomes. J Surg Res. 2013;181:106-13.

36. Vonlanthen R, Slankamenac K, Breitenstein S, Puhan MA, Muller MK, Hahnloser $D$, et al. The impact of complications on costs of major surgical procedures: a cost analysis of 1200 patients. Ann Surg. 2011;254:907-13.

37. Mclsaac DI, Saunders C, Hladkowicz E, Bryson GL, Forster AJ, Gagne S, et al. PREHAB study: a protocol for a prospective randomised clinical trial of exercise therapy for people living with frailty having cancer surgery. BMJ Open. 2018;8:1-8.

38. Zegers M, de Bruijne MC, de Keizer B, Merten H, Groenewegen PP, van der Wal G, et al. The incidence, root-causes, and outcomes of adverse events in surgical units: implication for potential prevention strategies. Patient Saf Surg. 2011;5:13. Available at: http://pssjournal.biomedcentral.com/ articles/10.1186/1754-9493-5-13.

\section{Publisher's Note}

Springer Nature remains neutral with regard to jurisdictional claims in published maps and institutional affiliations.

Ready to submit your research? Choose BMC and benefit from

- fast, convenient online submission

- thorough peer review by experienced researchers in your field

- rapid publication on acceptance

- support for research data, including large and complex data types

- gold Open Access which fosters wider collaboration and increased citations

- maximum visibility for your research: over 100M website views per year

At BMC, research is always in progress.

Learn more biomedcentral.com/submissions 